\title{
Mapeamento da produção científica qualificada na área de acessibilidade no ambiente construído (2008 a 2018)
}

\author{
Mapping of the qualified scientific production in the area of \\ accessibility in the built environment (2008 to 2018)
}

\author{
ANGELINA DIAS LEÃO COSTA \\ Doutora em Engenharia Civil, Universidade Federal da Paraíba (UFPB), \\ angelinadlcosta@yahoo.com.br \\ LÍVIA DE OLIVEIRA PEREIRA \\ Graduanda em Arquitetura e Urbanismo, Universidade Federal da Paraíba (UFPB), \\ livia_oliveirap@hotmail.com
}

\begin{abstract}
RESUMO
O presente trabalho mapeia e analisa a produção científica qualificada da última década na área da acessibilidade no ambiente construído, temática de elevada importância na conjuntura da arquitetura aliada à qualidade de vida e social. A partir do estudo e levantamento de dados baseados nas edições do Encontro Nacional de Ergonomia do Ambiente Construído e Seminário Brasileiro de Acessibilidade Integral (ENEAC), juntamente à pesquisa em variados periódicos nacionais e internacionais, foi possível a delimitação da recorrência de temas e objetos de estudo nas publicações qualificadas analisadas acerca da acessibilidade. Esta catalogação da produção permitiu ainda a estruturação de uma linha do tempo e comportamental das publicações ao longo do período estudado, além da criação de um mapa locando os pólos de publicação no Brasil. Os principais resultados da pesquisa revelam a centralização da maior parte da produção catalogada em algumas poucas universidades nacionais, concomitante à aglomeração dos pólos de produção de acessibilidade no ambiente construído em 2 regiões do país, além de apontar diferenças explícitas entre a produção e temáticas mais usuais das publicações nos âmbitos locais e internacionais.
\end{abstract}

PALAVRAS-CHAVE: Acessibilidade; Ambiente construído; Catalogação; Produção científica; ENEAC.

\section{ABSTRACT}

The present study maps and analyzes the qualified scientific production of the last decade in the area of accessibility in the built environment, a theme of great importance in the conjuncture of architecture allied to the quality of life and social experiences. From the study and data collected based on the editions of the 'Encontro Nacional de Ergonomia do Ambiente Construído e Seminário Brasileiro de Acessibilidade Integral' (ENEAC) - an important meeting conference about the subject - 


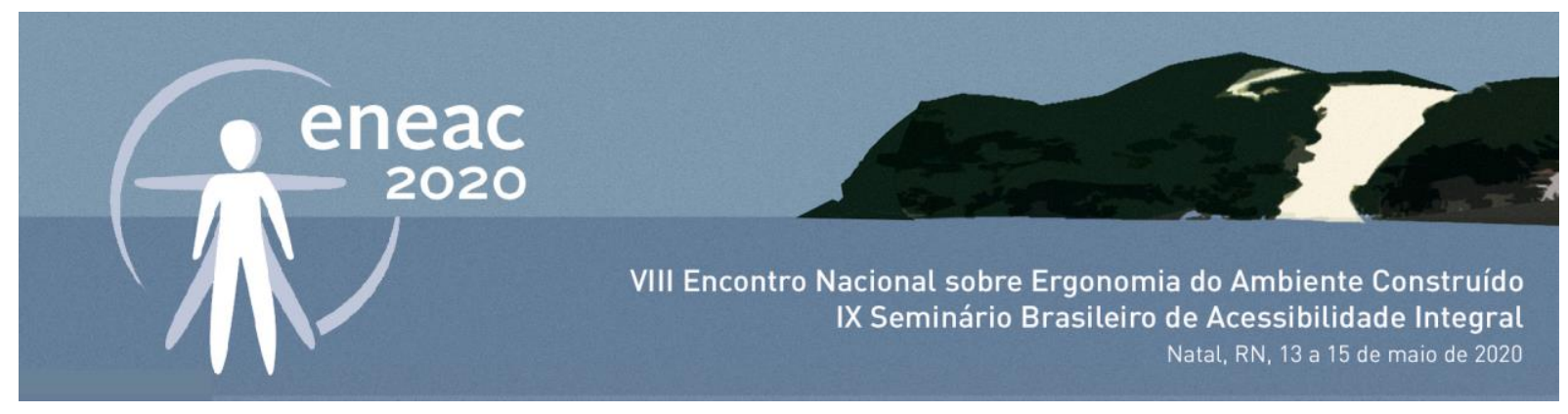

and the review of many national and international journals, it was possible to delimit the recurrence of authors, themes and objects of study in the qualified publications analyzed about accessibility. This cataloguing of the production allowed the creation of a time and performance line of the publications throughout the period of time established in this research, as well as the making of a map locating the areas in Brazil that publish the most about the theme. The results of the research reveal a centralization of most of the production cataloged in a few universities, which can also be associated to the agglomeration of the poles of production about accessibility in only 2 regions of the country. Besides that, this research managed to point out explicit differences between the production and the most usual subjects of the publications in Brazil and other international countries.

KEYWORDS: Accessibility; Built environment; Cataloguing; Scientific production; ENEAC.

\section{INTRODUÇÃO}

Este artigo trata da temática da acessibilidade no ambiente construído, o qual pode ser caracterizado como o espaço criado pelo homem como palco para atender suas atividades, intrinsecamente relacionadas aos padrões sociais que gerem a comunidade. Conforme Zevi (1996), o ambiente construído será aquele que remete ao espaço arquitetônico, o ambiente da convivência, passível de apropriação e modificações pelos usuários que o habitam. Já a acessibilidade é definida, pela Associação Brasileira de Normas Técnicas na NBR 9050 (ABNT, 2015), como "possibilidade e condição de alcance, percepção e entendimento para a utilização com segurança e autonomia de edificações, espaço, mobiliário, equipamento urbano e elementos". Tal conceito propõe a criação de melhorias que possibilitem a utilização de quaisquer elementos do espaço por pessoas, inclusive as que apresentam dificuldades sensoriais ou mentais (PRADO; LOPES; ORNSTEIN, 2010).

No Brasil, é estimado que cerca de 46 milhões de habitantes convivam com algum tipo de deficiência, segundo o último Censo (IBGE 2010). Tal estimativa, que caracteriza $24 \%$ da população, aliada aos $8 \%$ de idosos locais, demonstra a grande escala da acessibilidade, que adentra em um contexto de importância social, questões de cidadania e consciência coletiva.

Esta pesquisa objetivou identificar a produção científica no campo da acessibilidade no ambiente construído no país - delimitada entre os anos de 2008 e 2018 -, investigando o cenário das publicações acerca do tema e analisando as temáticas mais usuais da aplicabilidade do ambiente acessível, à partir do levantamento dos anais do ENEAC. O Encontro Nacional de Ergonomia do Ambiente Construído ocorre simultaneamente ao Seminário Brasileiro de Acessibilidade Integral, viabilizando o aprofundamento da comunidade acadêmica em ambas as linhas de pesquisa, intrinsecamente conectadas, pois não se pode pensar em ergonomia aplicada ao ambiente construído sem considerar a acessibilidade (VILLAROUCO, 2018).

Os resultados desta análise inédita são importantes, à medida que possibilitam o repasse e síntese dos dados coletados para demais núcleos de pesquisa, fomentando tais discussões na formação do profissional arquiteto e favorecendo a construção de ambientes mais acessíveis. 


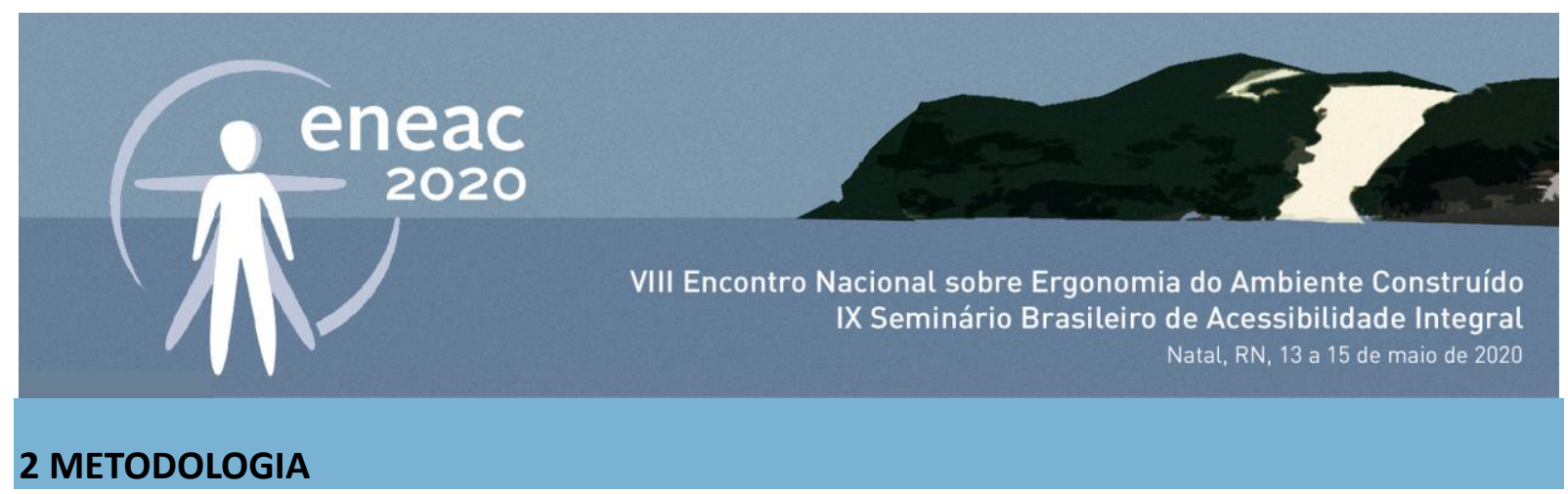

Composto por um caráter bibliométrico (análise quantitativa e estatística de dados científicos) e associado às estratégias de seleção, o método da presente pesquisa foi dividido em duas fases distintas, com suas respectivas etapas:

Fase A: Coleta e filtragem. Esta fase inicial consistiu em um levantamento de dados mais generalizado, com o intuito de desenvolver um embasamento direto para o então afunilamento e filtragem dos dados de estudo. Dividiu-se nas seguintes etapas: 1- Pesquisa bibliográfica referencial: foi realizado um levantamento dos Anais do evento ENEAC, a partir do acesso virtual aos sites disponíveis e checagem de todo o material produzido nas edições da última década, nos respectivos anos de 2009, 2011, 2013, 2014, 2016 e 2018; 2- Filtragem dos dados coletados: os dados recolhidos foram filtrados em categorias delimitadas de forma à melhor organizar as informações do evento. 0 levantamento das publicações foi dividido de acordo com a Seção Técnica dos artigos, os autores - e seus grupos de pesquisa, as palavras-chaves e os periódicos encontrados na bibliografia, possibilitando a criação de listas enumeradas com base em fatores de recorrência.

Fase B: Análise e Síntese: Esta fase concentrou o processo analítico dos dados coletados e filtrados na etapa anterior, além da geração de material gráfico. Dividiu-se nas seguintes etapas: 3- Análise das informações coletadas: foram analisadas as informações obtidas resultantes das triagens já realizadas, mapeando origens de publicações e delineando o cenário da pesquisa temática no país a partir do conhecimento dos temas mais trabalhados e os grupos de pesquisa mais ativos. 4Síntese: foram criadas listas de referências que podem auxiliar demais pesquisadores a fundamentar e divulgar suas publicações, além da finalização do banco de dados para disponibilização.

\section{Figura 1: Figura esquemática da metodologia utilizada.}

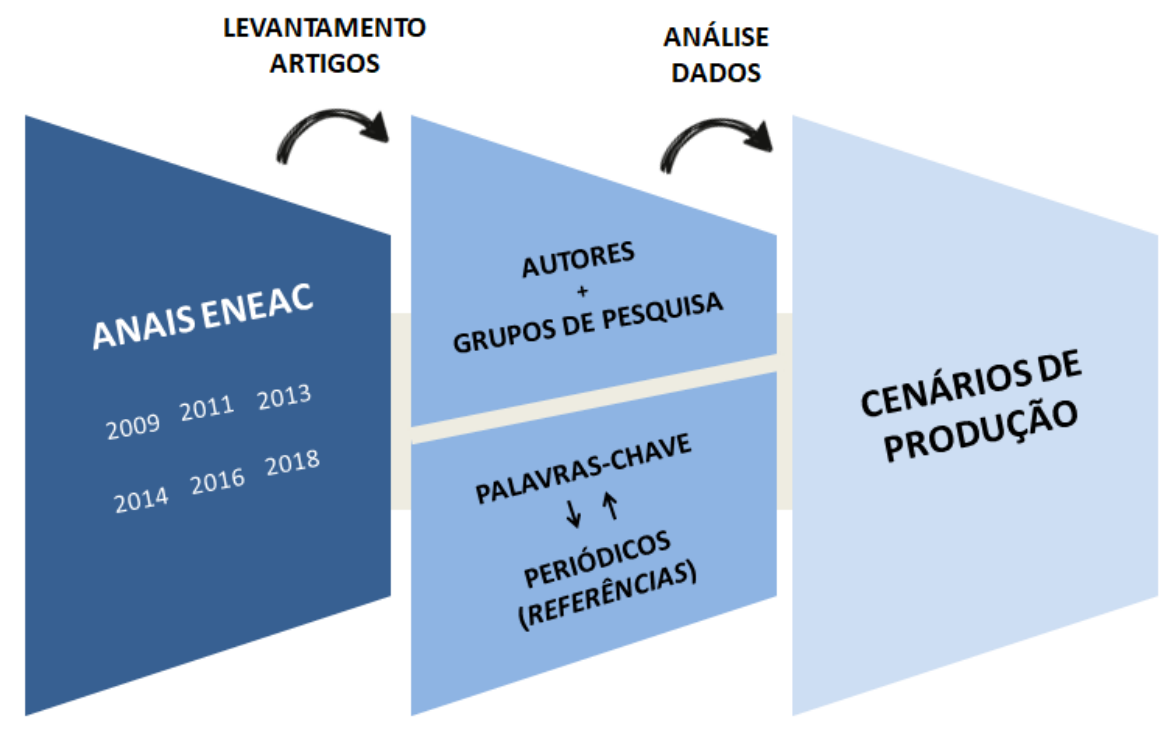

Fonte: Autores, 2019. 


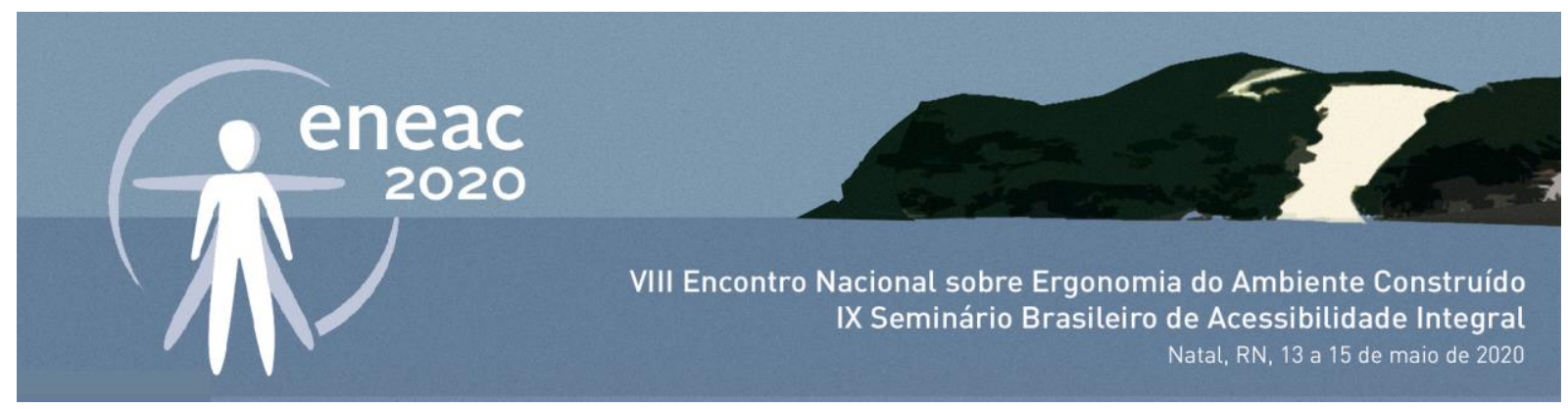

\section{FILTRAGEM INICIAL: A PRODUÇÃO DO ENEAC NA ÚLTIMA DÉCADA}

\section{Levantamento geral}

O início da construção da base de dados da pesquisa consistiu na catalogação de todas as publicações referentes ao Encontro Nacional de Ergonomia do Ambiente Construído (ENEAC) em suas últimas seis edições. Considerando-se que a primeira realização do evento - na cidade de Recife/PE - ocorreu em 2007 e não se adentra na década de estudo, o levantamento dos dados foi organizado em ordem de tempo crescente, partindo desde a segunda edição do ENEAC até a última datada, como pode ser observado na figura 2 :

Figura 2: Gráfico contendo o número de publicações e autores ligados às edições do ENEAC.

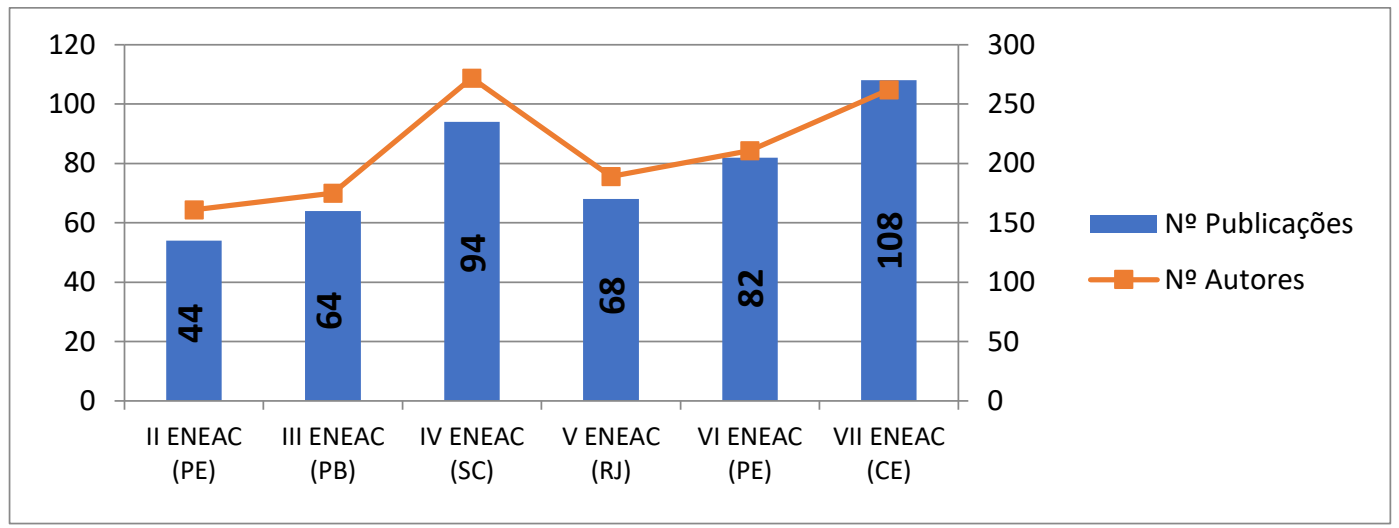

Fonte: Autores, 2019.

Houve um aumento gradual da quantidade de pesquisadores e publicações ao longo dos anos do evento em suas seis edições, das quais quatro ocorreram na região Nordeste do país. Observa-se, também, que as edições de maior número de artigos e autores foram as do IV ENEAC, VI ENEAC e VII ENEAC, localizadas, respectivamente, nas cidades de Florianópolis/SC, Recife/PE e Fortaleza/CE.

\section{Universidades e grupos de pesquisa}

A utilização de conceitos e aplicações da acessibilidade e ergonomia aos estudos do ambiente construído tem sido tratada de modo crescente por grupos de pesquisa brasileiros nas duas últimas décadas (VILLAROUCO, 2018). As numerosas pesquisas conduzidas no decorrer deste período ajudaram a desenvolver métodos e ferramentas de estudo, consolidando importantes e atuais temáticas para a área.

Foram encontrados 835 nomes de pesquisadores de todo o Brasil vinculados às publicações das edições do ENEAC. Foram ainda catalogados (por meio de plataformas digitais) os grupos de pesquisa vinculados a cada um dos autores citados nas publicações do evento. Em seguida, foi-se realizada uma triagem analisando quais destes grupos concentravam o maior número de autores que publicaram no ENEAC.

A seguir são apresentados os 10 grupos que mais publicaram no evento - dentre a área de acessibilidade no ambiente construído (tabela 1): 


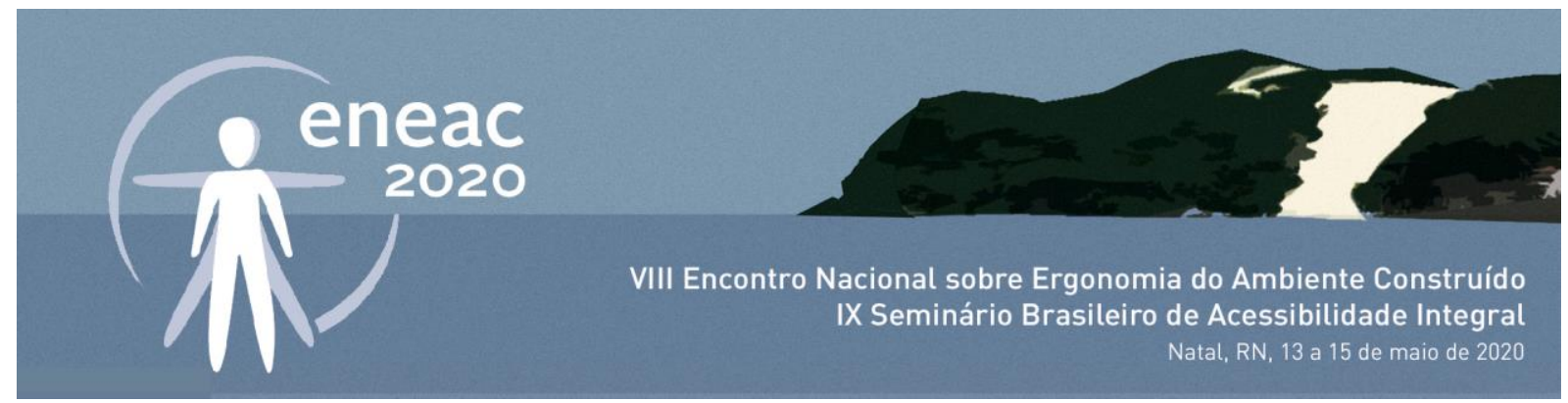

Tabela 1: Grupos de pesquisa mais atuantes.

\begin{tabular}{|c|c|c|c|}
\hline N. $\stackrel{9}{2}$ & GRUPO DE PESQUISA & INSTITUIÇÃO & $\begin{array}{l}\text { QUANTITATIVO DE } \\
\text { AUTORES LIGADOS À } \\
\text { PRODUÇÃO NO ENEAC }\end{array}$ \\
\hline 1 & Ergonomia aplicada ao Ambiente Construído & UFPE & 12 \\
\hline 2 & Ergonomia e usabilidade de produtos, sistemas e produção & UFPE & 12 \\
\hline 3 & $\begin{array}{c}\text { DESENHO UNIVERSAL NO PROJETO DE ARQUITETURA: } \\
\text { investigação, ensino e prática da acessibilidade plena no ambiente } \\
\text { construído }\end{array}$ & UNICAMP & 9 \\
\hline 4 & AcessUs: Acessibilidade, Tecnologia, Percepção e Qualidade & UFPB & 8 \\
\hline 5 & Gestão de Design (Laboratório de Design e Usabilidade) & UFSC & 8 \\
\hline 6 & LABERGO design - Laboratório de Ergonomia e Design Universal & UFPE & 7 \\
\hline 7 & $\begin{array}{l}\text { GMETTA: Grupo Multidisciplinar de Ergonomia do Trabalho e } \\
\text { Tecnologias Aplicadas }\end{array}$ & UFSC & 7 \\
\hline
\end{tabular}

Fonte: Autores, 2019.

Ao analisar a tabela 1 e a figura 1, fica claro que a Universidade Federal de Santa Catarina (UFSC) e a Universidade Federal de Pernambuco (UFPE) foram as mais expressivas na esfera da temática da acessibilidade, estando associadas diretamente a mais de um grupo de pesquisa. Tal fato reafirma-se se comparado também aos dados previamente coletados na análise do evento: as edições de maior número de publicações e pesquisadores também foram realizadas nas cidades de Florianópolis/SC (IV ENEAC) e Recife/PE (VI ENEAC).

\section{A procura por palavras-chave}

Ainda com base nos dados levantados nos anais das edições escolhidas do ENEAC, foi notável a diversidade de palavras-chave apresentadas nos resumos, sendo contabilizadas 378 no total, caracterizadas por palavras únicas, expressões ou frases atribuídas aos temas relatados nos artigos. Observando-as, as palavras-chave foram classificadas e agrupadas em 4 categorias que abrangem majoritariamente o conjunto (figura 3). Foram estas: Conceitos, Usuários, Ambientes e Outros.

Figura 3: Gráfico com a recorrência dos tipos de palavras-chave encontrados.

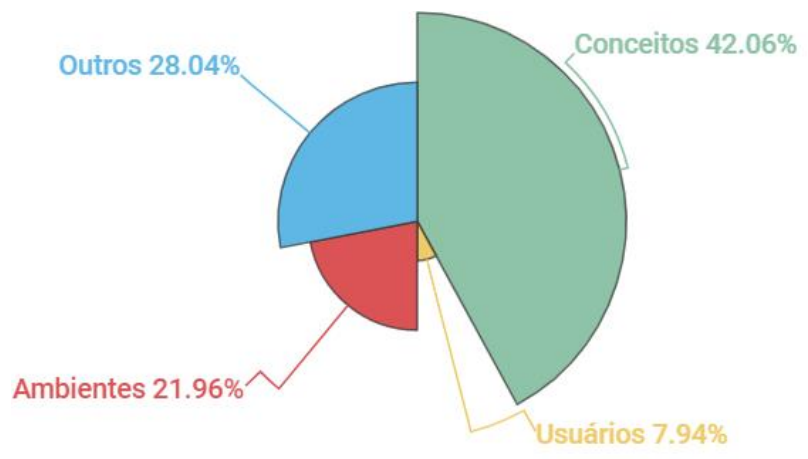

Conceitos Usuários Ambientes Outros 


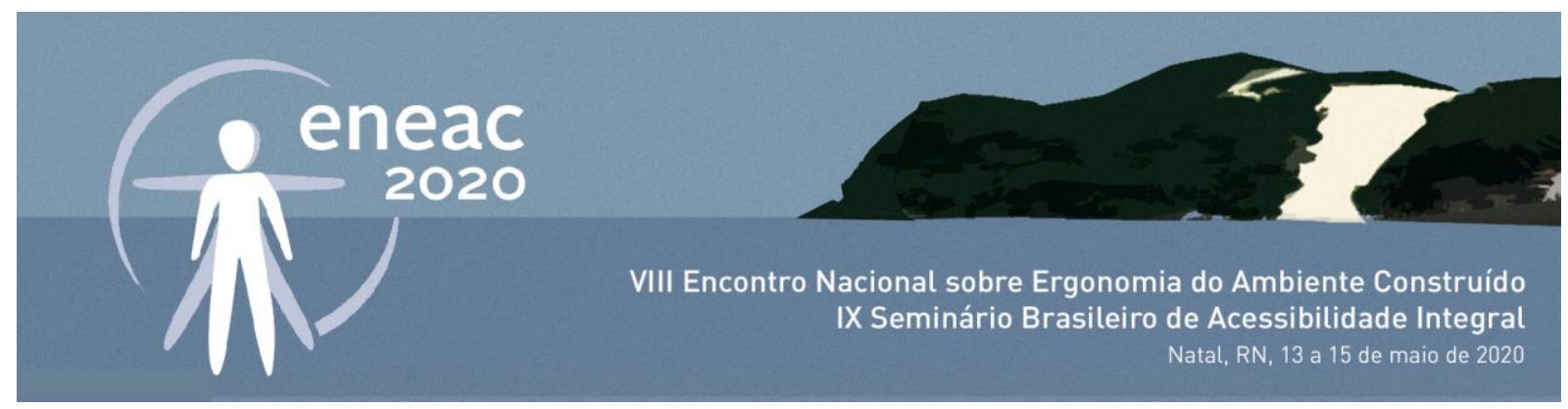

A categoria Conceitos engloba noções mais gerais do universo da acessibilidade no ambiente construído, tais como desenho universal, NBR 9050 e inclusão. Em Usuários, foram catalogadas as palavras-chave aplicadas a diferentes grupos de pessoas, tais como idosos, crianças e Alzheimer; já a divisão Ambientes refere-se aos espaços construídos, com exemplares como habitação de interesse social, salas de aula e banheiros. Por fim, a categoria Outros engloba os termos que não se encaixaram nas condições anteriores, como iluminação, atividades domésticas e mobiliário urbano.

Como pode ser observado no gráfico, a categoria mais recorrente dentre as 378 palavras-chaves é a de Conceitos, com 159 exemplares. Seguindo esta, encontra-se a de Outros, com cerca de $28 \%$ do total e 106 exemplares, além das palavras-chave dentre as categorias Usuários e Ambientes, que apresentam 30 e 83 exemplares, respectivamente. Tais resultados evidenciaram que as publicações relacionadas à acessibilidade e ergonomia do ambiente construído atrelam-se à questões metodológicas, resultando em uma menor variedade de pesquisas referentes a ambientes construídos e usuários.

Partindo do levantamento deste universo, foi-se realizada uma maior delimitação do conjunto encontrado, com base nos termos de maior recorrência nas publicações. As dez palavras-chave mais recorrentes, dentre o total, e suas respectivas quantidades de repetições foram: Acessibilidade (repetida 84 vezes), Ergonomia (35 vezes), Ergonomia do Ambiente Construído (18), Avaliação Pósocupação (15), Arquitetura (11), Ambiente Construído (11), Idoso(s) (10), Desenho Universal (10), Pessoa/usuário com Deficiência (9) e NBR 9050 (7). A distinção destas recorrências torna-se importante, pois permite um melhor entendimento do cenário de publicações acerca da acessibilidade e seus temas mais trabalhados.

Nenhuma das palavras-chaves escolhidas pela recorrência está categorizada na seção de Ambientes, estando 7 do conjunto total de 10 na camada de Conceito, como pode ser analisado na figura 4:

Figura 4: Gráfico com recorrência das palavras-chave classificadas por categorias.

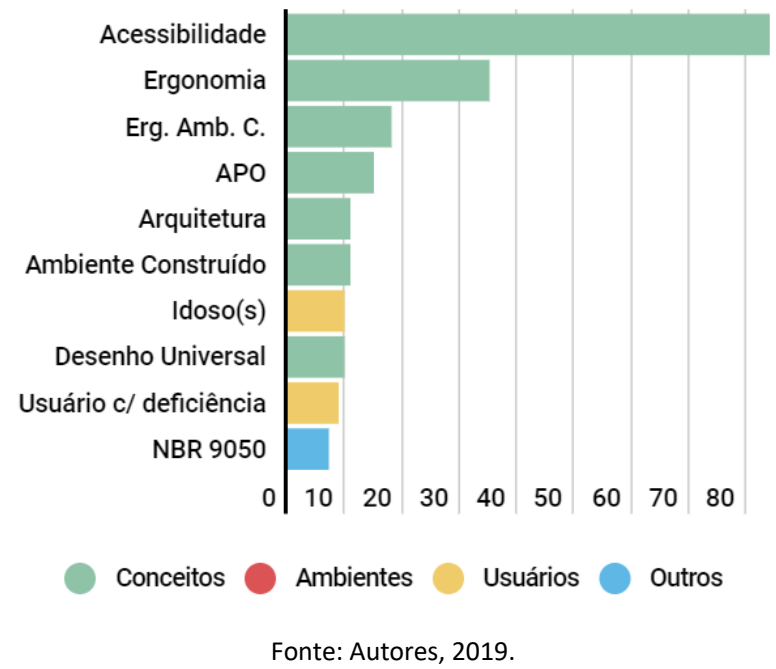

Vale ressaltar que a palavra-chave simples Acessibilidade foi a mais recorrente, pois, apesar da listagem conter demais variações do termo, estas não se encontravam dentre as mais repetidas e usuais. As 4 diferentes palavras-chaves encontradas entre os resumos das publicações do ENEAC que 


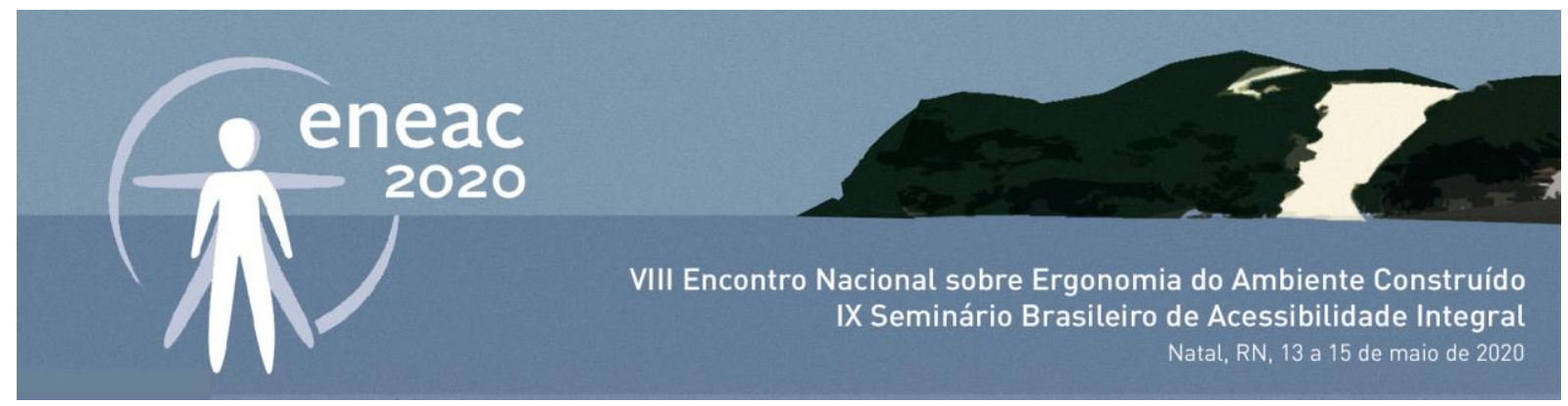

denotam os diferentes "tipos" de acessibilidade foram: Acessibilidade Espacial (recorrente 6 vezes), Acessibilidade Integral (3 vezes), Acessibilidade Efetiva (2) e Acessibilidade Física (2). Comparando-as ao uso único e mais geral da palavra Acessibilidade, repetida por mais de 80 vezes como palavrachave utilizada, fica evidente a necessidade de uma melhor delimitação do que é de fato a acessibilidade, sua conceituação.

A partir da análise, nota-se, também, a relevância das temáticas de ergonomia e técnicas de avaliação pós-ocupação dentre o universo de publicações catalogadas, sendo estas recorrentes objetos de estudo e publicações. Além disso, dentre os diversos tipos de usuários existentes e passíveis de abordagem nas pesquisas, percebe-se que os grupos de idosos e pessoas com deficiência - termo de cunho mais generalizado - foram os mais abordados dentre as publicações do grande evento nacional.

\section{APROFUNDAMENTO DE ESTUDO: O PANORAMA DAS PUBLICAÇÕES CIENTÍFICAS}

\section{Periódicos e artigos}

A extensa bibliografia atrelada às publicações das edições analisadas dos anais do ENEAC permitiu uma associação direta entre o tema de estudo e as revistas acadêmicas, sendo estas importantes referências para as publicações.

Foram encontrados 245 periódicos nas referências bibliográficas de todas as publicações divulgadas no ENEAC ao longo dos anos estudados. Dentre estes, 73 fazem parte da área Arquitetura, Urbanismo e Design da CAPES, a mais relevante se associada à temática da acessibilidade em espaços edificados.

É importante ressaltar a classificação de periódicos baseada no Qualis, o sistema brasileiro de avaliação de periódicos, mantido pela CAPES, que classifica as revistas baseado em qualidade $(A, B, C)$ e área de avaliação. Para este estudo, inicialmente, era interessante aprofundar-se apenas em revistas melhor classificadas: A1, A2, B1 ou B2. Entretanto, do conjunto de 245 periódicos encontrados, apenas 44 cumprem este requisito, sendo destes 24 periódicos brasileiros e 20 internacionais, como pode ser analisado na figura 5 :

Figura 5: Diagrama do quantitativo dos periódicos selecionados.

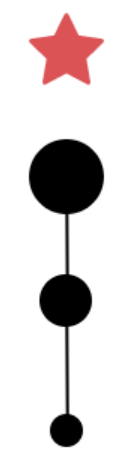

\section{5}

Total de periódicos encontrados.

\section{$29.8 \%$}

Periódicos na categoria Arquitetura, Urb. e Design.

$58.9 \%$ destes

Periódicos classificados em A1, A2, B1 ou B2.

$55.8 \%$ destes

Periódicos nacionais. 


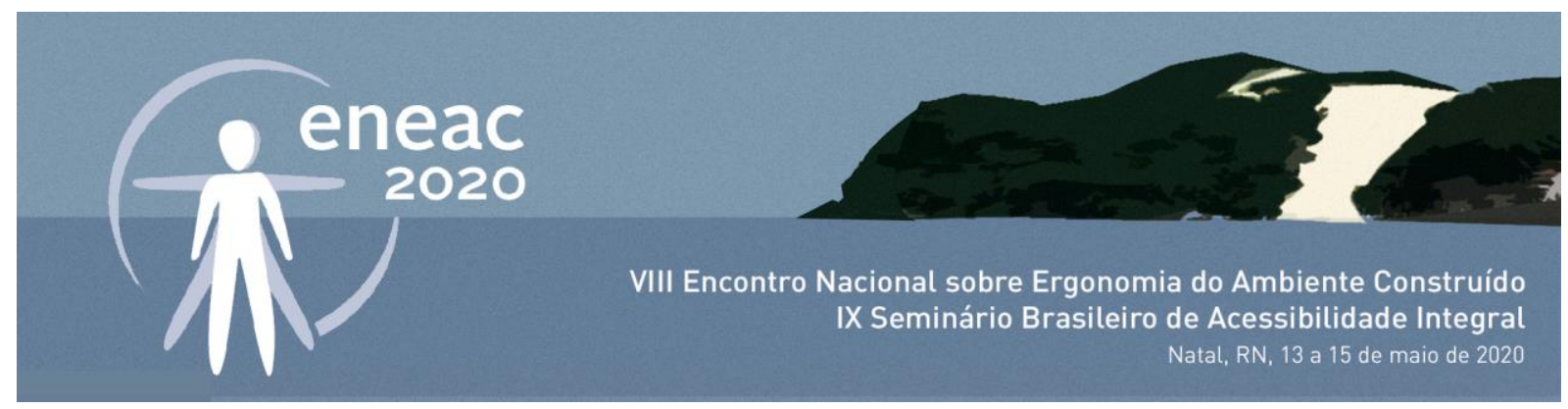

Analisando tais dados, percebe-se que mais da metade dos periódicos pertinentes está nas categorias de melhor qualificação da Qualis, com grande parte destes sendo de origem brasileira. Tais dados direcionam que a publicação das pesquisas dos grupos brasileiros ainda vem ocorrendo, na maioria dos casos, em português.

Tendo em vista o grande número de revistas encontradas, fez-se necessária a delimitação de um grupo menor de unidades para avaliação. Baseado em uma relação de qualificação Qualis (no quadriênio 2013-2016) e recorrência bibliográfica nas referências das publicações do ENEAC, o enfoque de estudo foi reduzido para dez periódicos de interesse, como verificado na tabela 2 :

Tabela 2: Periódicos escolhidos por recorrência e suas classificações.

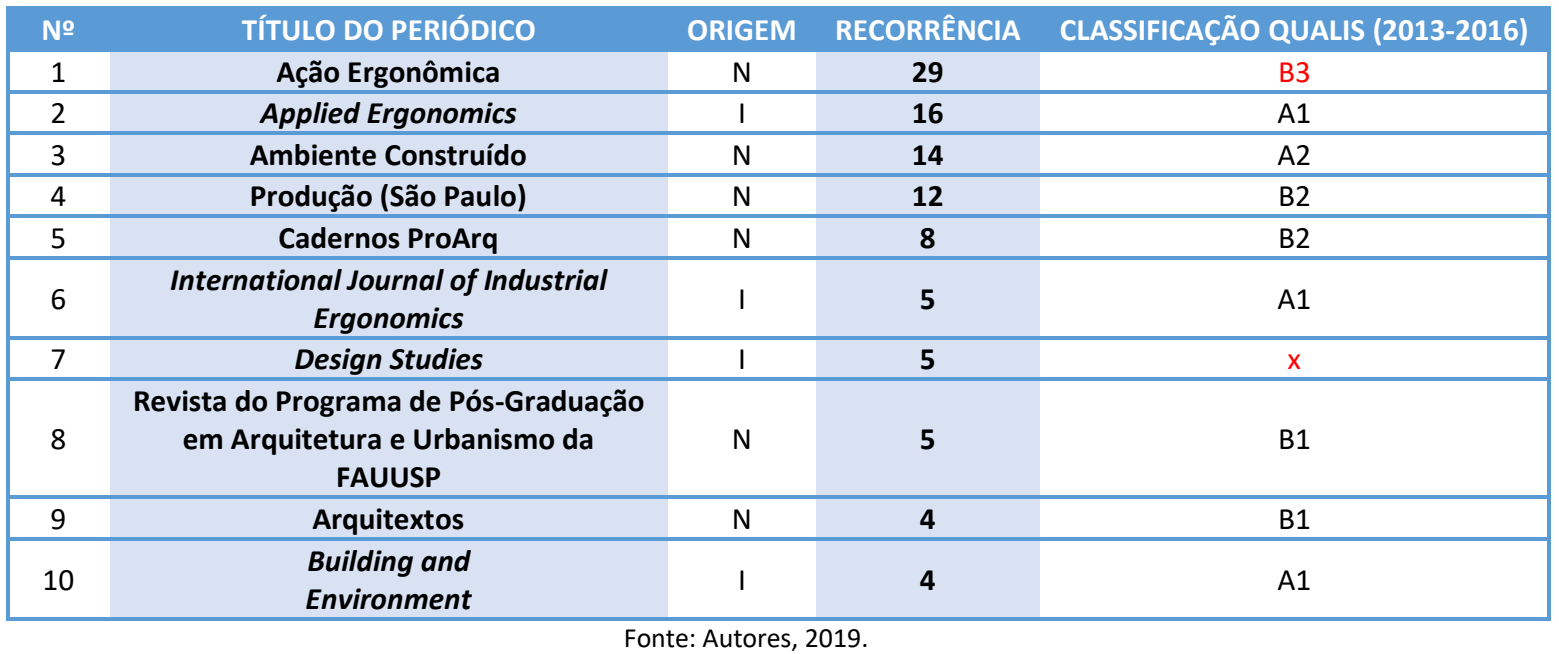

Dos 10 periódicos escolhidos mais recorrentes e melhor classificados, seis são nacionais e quatro internacionais. No entanto, vale salientar a exceção do periódico Ação Ergonômica: sendo o mais referenciado, por uma significativa margem, optou-se por considerá-lo na pesquisa, apesar de sua classificação 'B3' estar abaixo da inicialmente desejada. Além deste, o periódico Design Studies, de grande prestígio internacional, também foi considerado na análise, tendo em vista que não apresenta classificação Qualis no quadriênio, para a área, provavelmente pela falta de publicações de grupos nacionais na revista.

A fim de melhor entender a dimensão e o panorama da produção em torno do tema da acessibilidade no ambiente construído por entre tais periódicos de destaque, foram utilizadas as dez palavras-chave mais recorrentes entre as publicações do ENEAC - as mesmas já previamente analisadas - como ferramenta de busca e afunilamento de resultados nas páginas digitais online das revistas eletrônicas. A pesquisa delimitada por estas palavras-chave resultou em diversos artigos encontrados, sendo apenas levados em consideração para a pesquisa àqueles relacionados ao tema da acessibilidade no ambiente construído e que possuíssem as palavras-chave definidas - estando estas nas próprias palavras-chave dos artigos ou encontradas em seus títulos. Além da essencial presença das palavras-chave nas publicações, é necessário relembrar que, para estas adentrarem nos parâmetros de avaliação, as mesmas devem ter sido publicadas na fração temporal de estudo deste trabalho - de 2008 a 2018. 


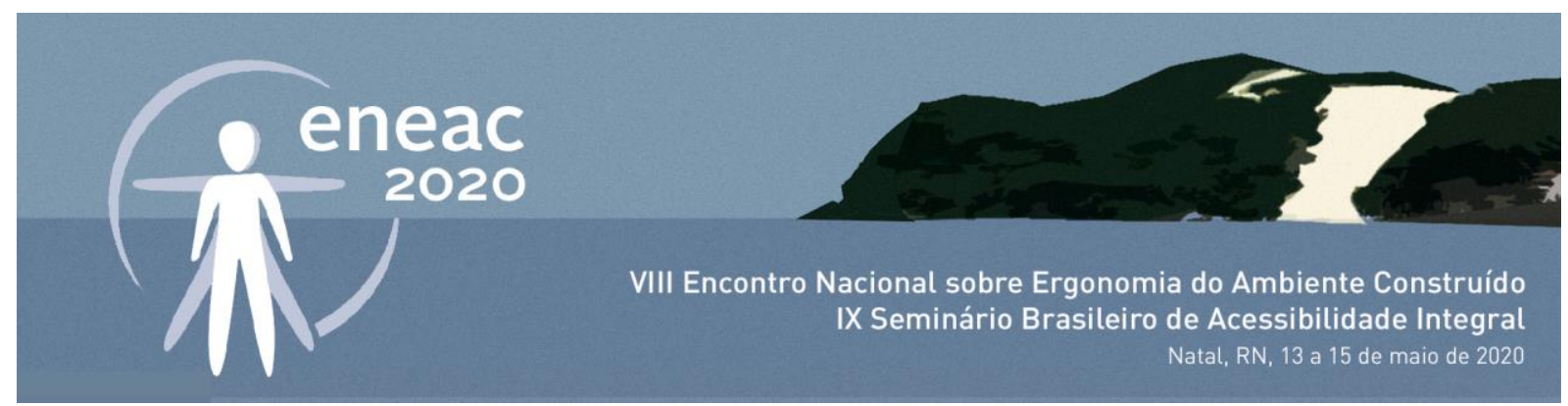

\section{Periódicos nacionais}

A fim de analisar a quantidade de artigos relacionados à acessibilidade no ambiente edificado publicada nos periódicos brasileiros, foi realizada a associação entre as palavras-chave encontradas nas publicações dos ENEAC's e os sites de pesquisa das referentes revistas. É importante ressaltar que, para valor de estudo, a pesquisa considerou também sinônimos das palavras-chave "usuário com deficiência/deficiente", tendo em vista que - neste caso - diferentes expressões podem significar o mesmo.

Os resultados obtidos pela procura de artigos válidos para o presente estudo, ao serem analisados, revelaram um número total nos 6 periódicos nacionais de 56 publicações - não muito alto, ainda mais se considerado o período de tempo analisado de uma década. No entanto, tais resultados podem ser explicados pela delimitação à qual os artigos foram submetidos, devendo estes estarem explicitamente relacionados a acessibilidade no ambiente construído, possuírem as específicas palavras-chave em sua estrutura e terem sido publicados somente entre os anos definidos. Os dados podem ser observados na figura 6:

Figura 6: Gráfico com a quantidade de artigos encontrados por periódicos nacionais x palavras-chave.

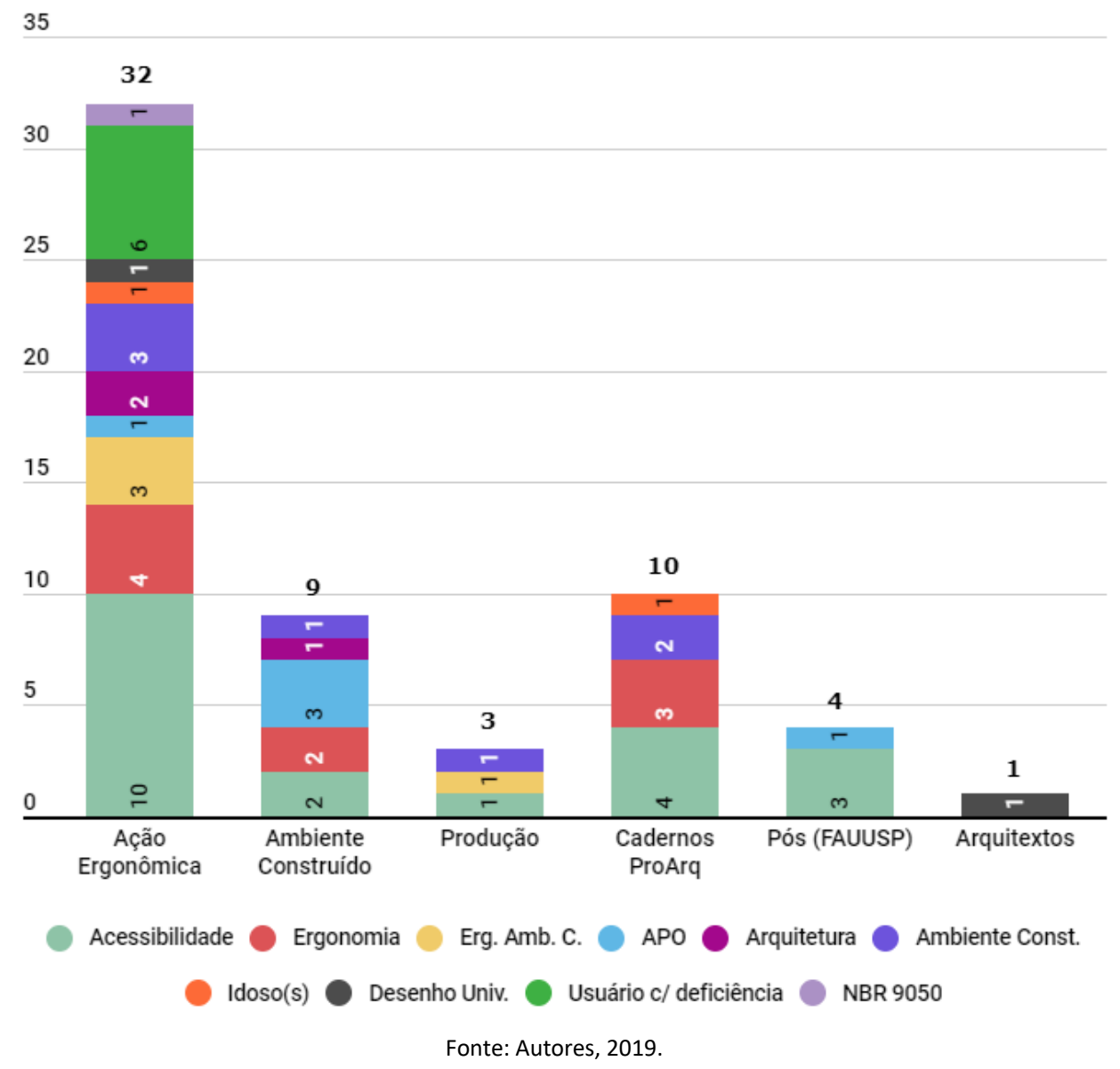

Percebeu-se visivelmente a superioridade do número de artigos encontrados no periódico Ação Ergonômica se comparado aos demais. Tal revista, apesar de sua classificação Qualis/CAPES, foi a 


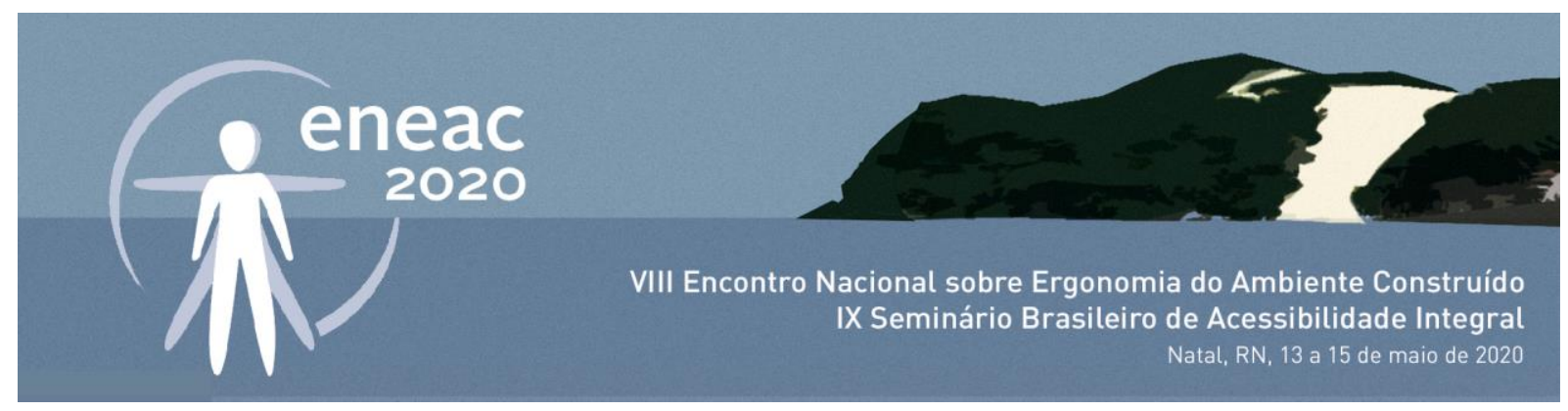

única a apresentar artigos para cada uma das palavras-chave inseridas na busca de seu acervo. Sendo um periódico de características multidisciplinares destinada a difundir os trabalhos científicos e técnicos em Ergonomia, a revista visa propiciar aos pesquisadores as bases conceituais, metodológicas e instrumentais para ações e projetos que visem melhorar de forma integrada a segurança, o conforto e a eficácia das atividades humanas mediante o estudo das interações das pessoas e dos ambientes que as acolhem (AÇÃO ERGONÔMICA, 2019).

O periódico Arquitextos, por sua vez, apresentou apenas um artigo que atendia as delimitações da busca. No entanto, esta específica revista não utiliza palavras-chave em seus artigos, deste modo, a única publicação encontrada apresentava a palavra-chave (Desenho Universal) em seu próprio título; além disso, muitos artigos são datados antes de 2008, não adentrando na delimitação desejada.

Percebeu-se, durante a análise, que as palavras-chaves mais gerais como Acessibilidade e Ergonomia foram as que mais se destacaram dentre os periódicos brasileiros, com 20 e 9 aparições nos artigos, respectivamente. Por outro lado, expressões mais específicas, como NBR 9050 e Desenho Universal, foram as menos encontradas em todas as revistas, associadas a Usuário com Deficiência, que apesar de um pouco mais recorrente, foi encontrada somente na revista Ação Ergonômica. Ademais, vale ressaltar a possibilidade de que o periódico Produção apresentou poucas publicações encontradas devido ao fato deste não ser majoritariamente voltado para a área de estudo em Arquitetura, e sim para o âmbito da Engenharia de Produção.

\section{Periódicos internacionais}

Para a análise das publicações dos periódicos internacionais, as mesmas palavras-chave definidas foram traduzidas para o inglês, a fim de possibilitar resultados. Estas palavras não foram frutos de uma tradução rigidamente literal, sendo levada em consideração para a interpretação uma pesquisa prévia nos periódicos da área da acessibilidade no ambiente construído, credibilizando a busca. No entanto, apenas 9 destas foram realmente utilizadas, tendo em vista que a palavra-chave NBR 9050 não apresenta real tradução para o inglês. A palavra-chave Acessibilidade foi traduzida para Acessibility; Ergonomia para Ergonomic(s); Ergo. do Amb. Construído para Environmental Ergonomic(s); Avaliação Pós-Ocupação para Post-Occupancy Evaluation; Arquitetura para Architecture; Ambiente Construído para Built Environment; Idoso(s) para Elderly/Seniors; Desenho Universal para Universal Design e Usuário com Deficiência para People with Disability/Disabled.

Com base nas 9 palavras-chave traduzidas, a busca realizada nas páginas digitais de cada periódico internacional resultou em 45 diferentes artigos. Apesar do número final de artigos encontrados nos periódicos internacionais - dentre os parâmetros - ter sido menor do que a quantidade total catalogada nas revistas nacionais, se considerado que foram analisados apenas 4 exemplares de periódicos estrangeiros, o número de publicações foi satisfatório. A relação entre as revistas, o número de artigos e as respectivas palavras-chave pode ser observado na figura 7 : 


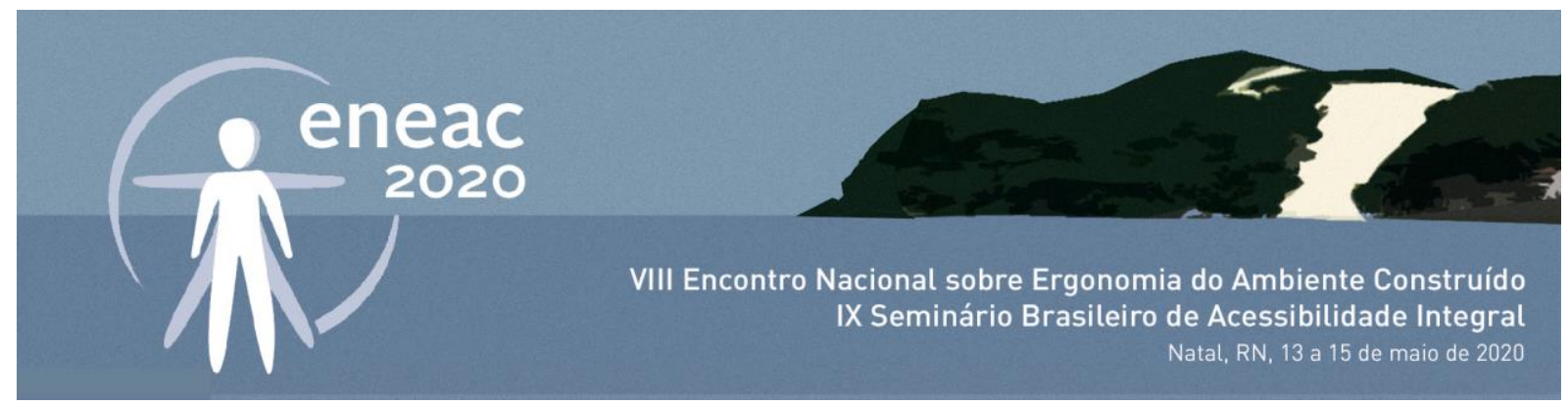

Figura 7: Gráfico com outros artigos encontrados nos periódicos internacionais com as mesmas palavras-chave.

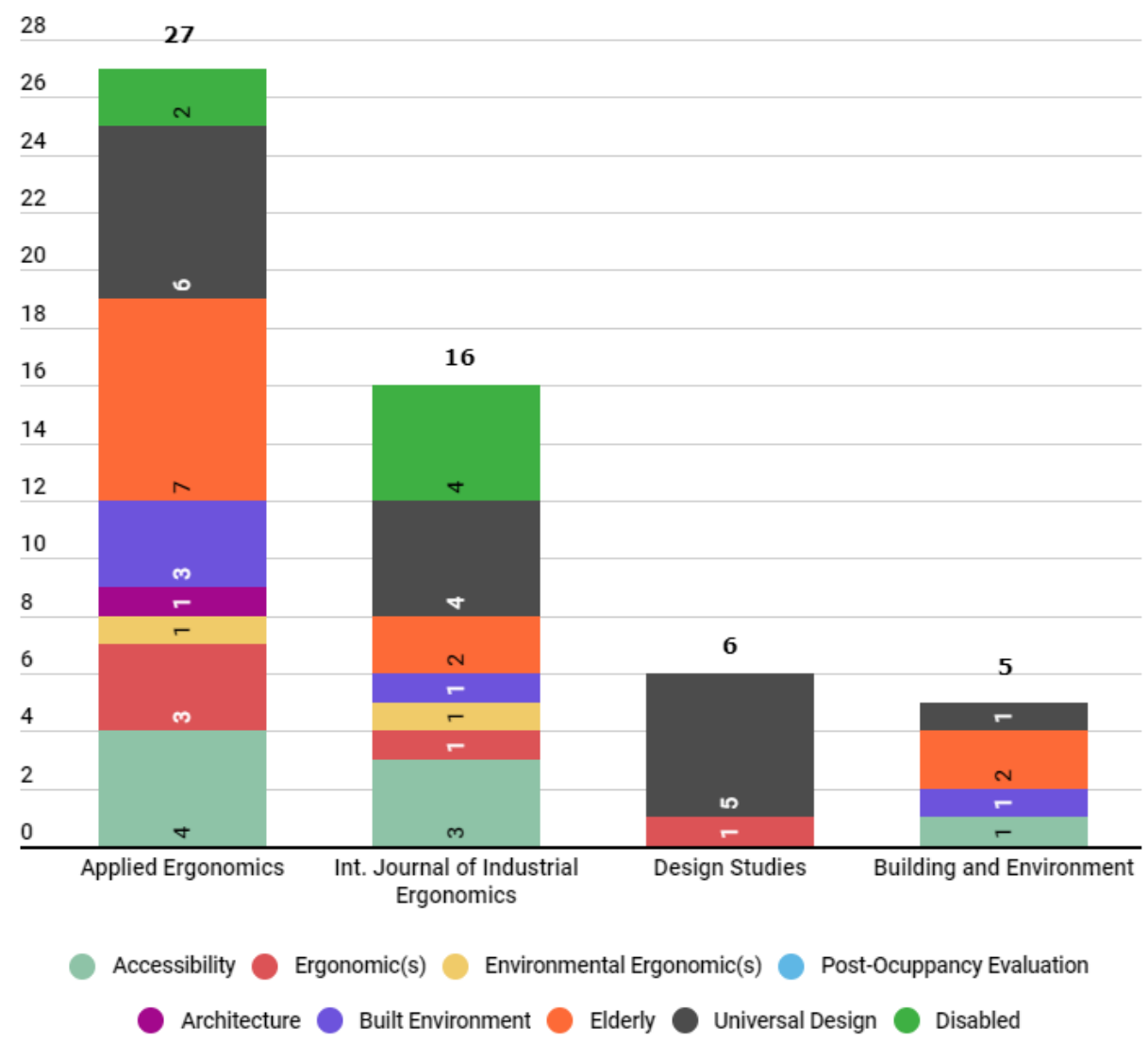

Fonte: Autores, 2019.

O periódico Applied Ergonomics apresentou o maior número de artigos dentre os demais, sendo este o segundo mais recorrente dentre todos os periódicos retirados das referências do ENEAC, como analisado previamente. A palavra-chave mais recorrente foi Universal Design, encontrada em todos os periódicos selecionados. Tal dado é interessante, pois demonstra a antagonia entre este resultado e os encontrados dentre os periódicos nacionais, nos quais a palavra-chave Desenho Universal equivalente ao Universal Design - aparece apenas 2 vezes entre todas as publicações catalogadas.

Ademais, algumas dificuldades foram encontradas na busca pelos artigos internacionais. A palavrachave Architecture, por exemplo, pouco apareceu dentre as publicações, mesmo quando associada a diferentes expressões. Isto pode ser explicado pelo fato de que grande parte das publicações destes periódicos encontra-se mais relacionada à temática do Design do que necessariamente à Arquitetura. Além disso, muitos dos artigos que de fato envolviam a acessibilidade no ambiente construído, e obedeciam aos demais parâmetros de pesquisa, não foram catalogados, tendo em vista que, por vários dos periódicos internacionais estarem em circulação há muitos anos, boa parte dos artigos possuía data de publicação anterior à década delimitada neste estudo. 


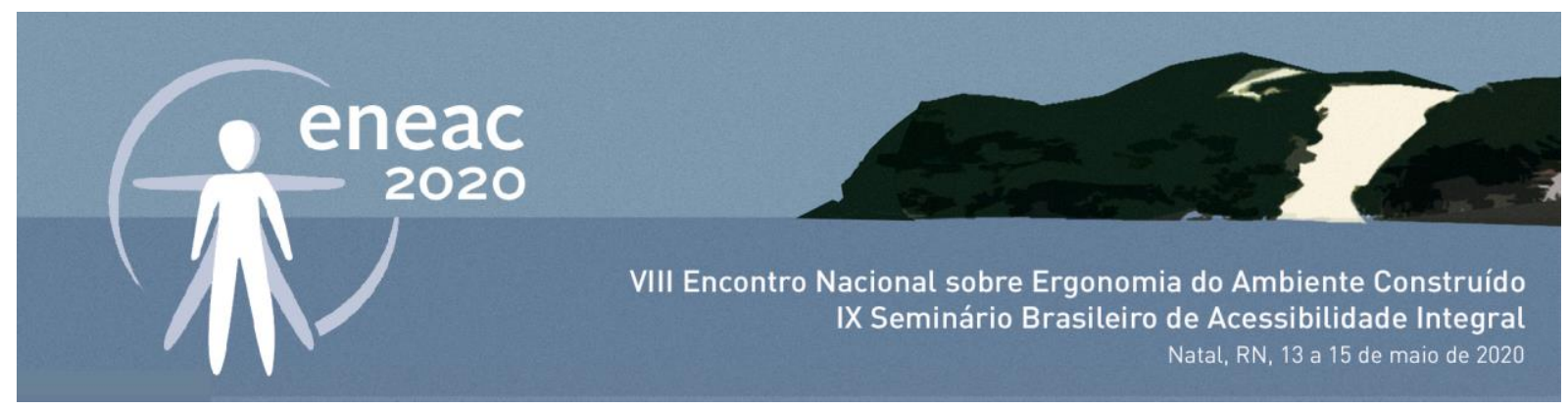

\section{O ATUAL CENÁRIO DE PRODUÇÃO}

A partir do estudo analítico dos resultados obtidos nas várias etapas de levantamento realizadas, torna-se possível uma melhor delineação do atual estado do meio de publicações científicas na área de acessibilidade no ambiente construído. A busca de artigos nos periódicos, baseada nas palavraschave específicas delimitadas, permitiu a percepção das temáticas mais trabalhadas na acessibilidade no ambiente construído. Estas temáticas diversas partem desde a avaliação da ergonomia e acessibilidade física de um espaço em questão até o estudo comportamental de determinados grupos de usuários que necessitam de cuidados especiais - com grande ênfase nos idosos.

Além disso, tendo em vista o universo de estudo de 101 publicações em periódicos nacionais e internacionais catalogadas no total - advindas dos periódicos -, surgiram inúmeros temas e palavraschave que não haviam sido delimitadas no presente trabalho, mas que se fazem importantes devido a sua constante recorrência. Por exemplo, temas relacionados à acessibilidade no ambiente construído que também abordavam habitações de interesse social e ambientes urbanos e públicos, além de métodos como o Wayfinding, encontraram-se presentes em muitos dos artigos revisados.

Foi possível observar também que o comportamento da divulgação de conhecimento científico da área de acessibilidade no ambiente construído não é constante. Como exemplificado no gráfico a seguir, o número de publicações por ano cresceu desde 2008, no entanto os ápices quantitativos são intercalados: as publicações acerca da temática avançam com o passar do tempo, mas a produção destes materiais científicos qualificados não é constante, variando - inclusive drasticamente - de acordo com os anos. Nota-se, no entanto, nos anos mais recentes - de 2016 em diante -, uma queda considerável na quantidade de publicações, que pode estar relacionada às dificuldades pelas quais passa a pesquisa no país desde então.

Figura 8: Gráfico com a quantidade de publicações catalogadas por ano.

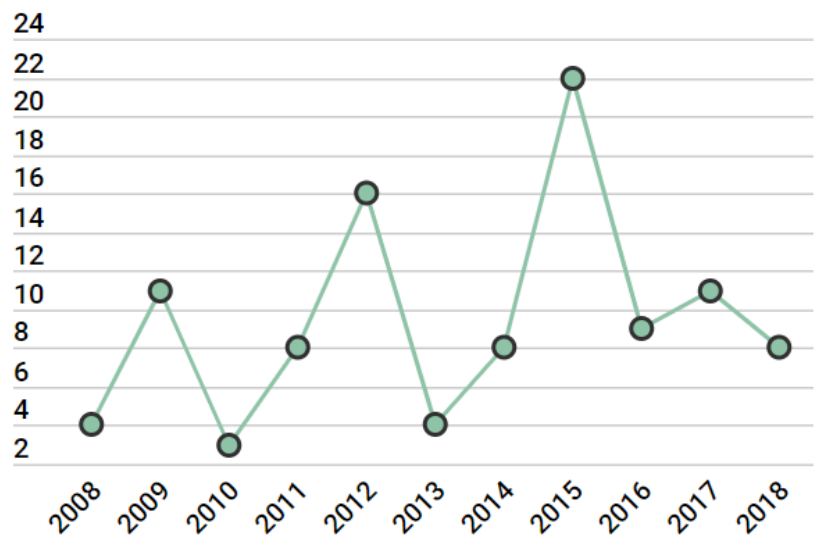

Publicações por ano

Fonte: Autores, 2019.

Para o mapeamento dos pólos de atuação nacionais acerca da produção científica da acessibilidade no ambiente construído, foi necessário localizar a origem das inúmeras publicações encontradas, provenientes dos periódicos selecionados. Esta análise apresentou um dado esperado: a origem da 


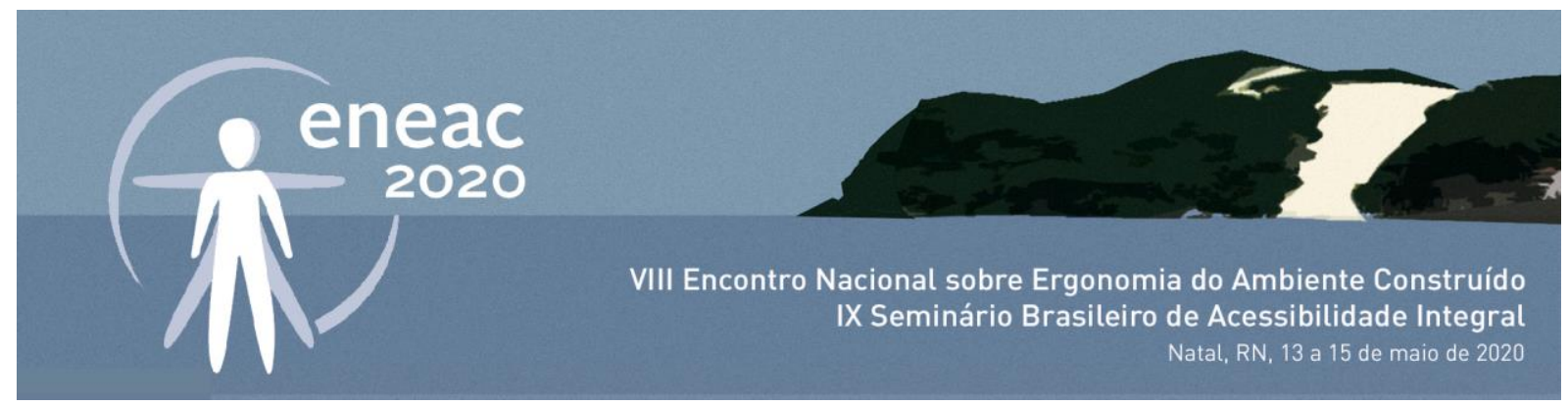

maioria dos artigos publicados se concentra em poucas regiões. Isto é, o total de publicações foi traçado para somente dez estados, sendo estes - organizados de forma crescente por quantidade de publicações: Pernambuco, Paraíba, Santa Catarina, São Paulo, Rio Grande do Sul, Minas Gerais, Rio de Janeiro, Rio Grande do Norte, Paraná e Distrito Federal.

Ao associar o tema da acessibilidade no ambiente construído aos grupos de pesquisa mais atuantes do país, às universidades de destaque e às origens das publicações, fica claro a recorrência de certas localizações em particular, estabelecidas como importantes núcleos da pesquisa temática no país. Deste modo, baseado nos dados levantados, foi possível a construção de um mapa de localização destes pólos de pesquisa na área, na figura:

Figura 9: Mapa de localização dos pólos de publicação no Brasil.

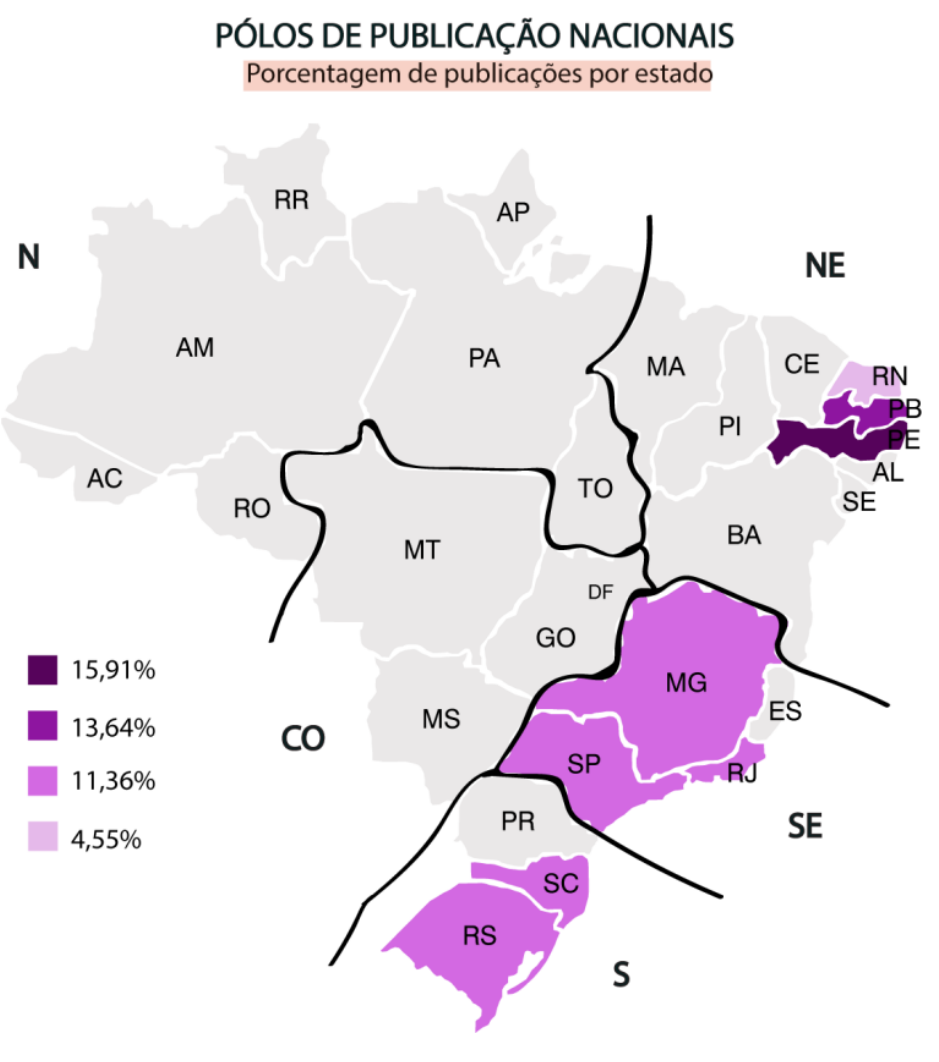

Fonte: Autores, 2019.

Através do mapa é possível, então, observar que a maior concentração das publicações científicas qualificadas catalogadas nesta pesquisa provém do estado de Pernambuco, que abriga também um dos grupos de pesquisa em acessibilidade mais ativos do país, o 'Ergonomia aplicada ao Ambiente Construído'. O estado da Paraíba aparece em segundo lugar dentre os pólos que mais publicam, originando precisamente $13,64 \%$ dos artigos encontrados dentre os 6 periódicos nacionais. Santa Catarina e São Paulo aparecem logo em seguida, resultado que se relaciona diretamente também à atuação de seus respectivos grupos de pesquisa em acessibilidade, que estão entre os 5 mais ativos do Brasil, como previamente estabelecido. 


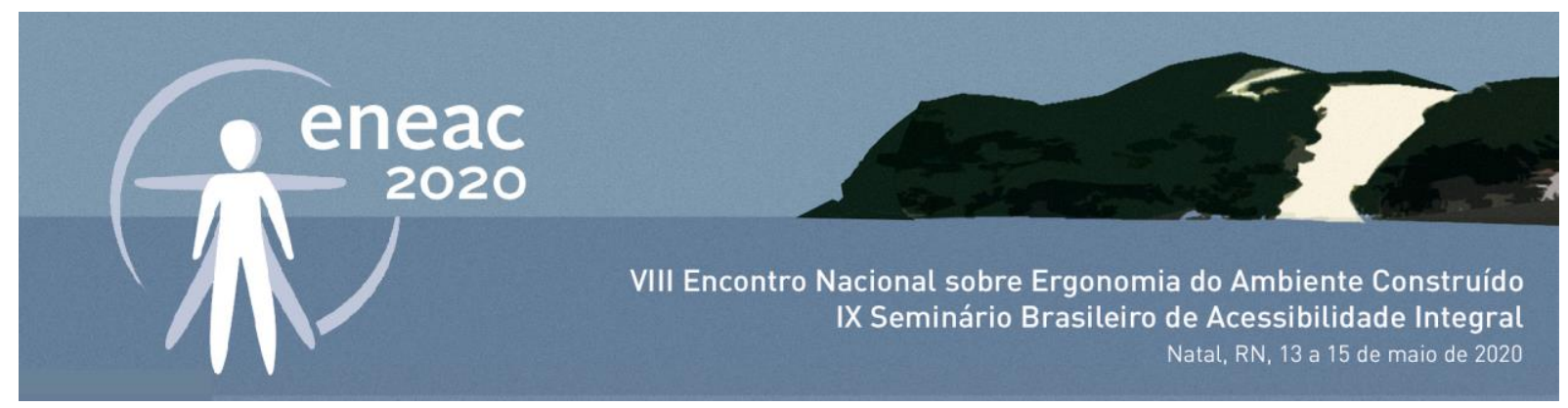

Evidencia-se, portanto, a necessidade de se ampliar a pesquisa nesta área, especialmente para as regiões Norte e Centro-Oeste, descentralizando-a dos poucos pólos nacionais.

\section{CONSIDERAÇÕES FINAIS}

É sabido que a temática da acessibilidade no ambiente construído encontra-se enraizada não só nos preceitos da qualidade de vida como também de convivência social. O processo de traçar o cenário contemporâneo da pesquisa qualificada da área propiciou a descoberta de diversas informações pertinentes para entender a atuação e abrangência dessa comunidade científica. Os dados analisados da última década demonstraram o avanço do número de publicações no Brasil, e a análise de material internacional permitiu observar o comportamento das publicações acerca do mesmo tema no exterior. No entanto, o interesse maior por esta temática ainda encontra-se concentrado em poucas regiões nacionais. O mapa de localização dos pólos de publicação, a grande repetição de vários periódicos na bibliografia dos artigos e o adensamento dos grupos de pesquisa em algumas universidades demonstram o atual e constante processo de expansão desta temática, especialmente nas regiões do Sul, Sudeste e Nordeste.

A importância desta pesquisa tornou-se clara quando associada ao desenvolvimento das ferramentas de difusão de conhecimento científico, que ditaram a obtenção de dados digitais cruciais para a realização das análises. Os resultados adquiridos podem guiar e auxiliar pesquisadores da área, ao apresentar os principais núcleos e grupos de pesquisa atuantes, as mais usuais temáticas abordadas, os tipos de usuários de maior enfoque e as revistas qualificadas que mais publicam materiais acerca do tema. Além disso, o repasse de informações e dados coletados para grupos de estudantes possibilita o fomento de discussões envolvendo a importância da proposta, de modo geral, estimulando o entendimento das questões acessíveis para futuros profissionais.

\section{AGRADECIMENTOS}

Agradecimento ao CNPQ pelo auxílio e financiamento em forma de bolsa de Iniciação Científica.

\section{REFERÊNCIAS}

ENCONTRO NACIONAL DE ERGONOMIA NO AMBIENTE CONSTRUÍDO E SEMINÁRIO BRASILEIRO DE ACESSIBILIDADE INTEGRAL, 2., 2009, Recife. Anais eletrônicos [...]. Recife: UFPE, 2009. 1 CD-ROM.

ENCONTRO NACIONAL DE ERGONOMIA NO AMBIENTE CONSTRUÍDO E SEMINÁRIO BRASILEIRO DE ACESSIBILIDADE INTEGRAL, 3., 2011, João Pessoa. Anais eletrônicos [...]. João Pessoa: UFPB, 2011. 1 CD-ROM.

ENCONTRO NACIONAL DE ERGONOMIA NO AMBIENTE CONSTRUÍDO E SEMINÁRIO BRASILEIRO DE ACESSIBILIDADE INTEGRAL, 4., 2013, Florianópolis. Anais eletrônicos [...]. Florianópolis: UFSC, 2013. 1 CD-ROM.

ENCONTRO NACIONAL DE ERGONOMIA NO AMBIENTE CONSTRUÍDO E SEMINÁRIO BRASILEIRO DE ACESSIBILIDADE INTEGRAL, 5., 2014, Rio de Janeiro. Anais eletrônicos [...]. Rio de Janeiro: PUC-Rio, 2014. 1 CD-ROM. 


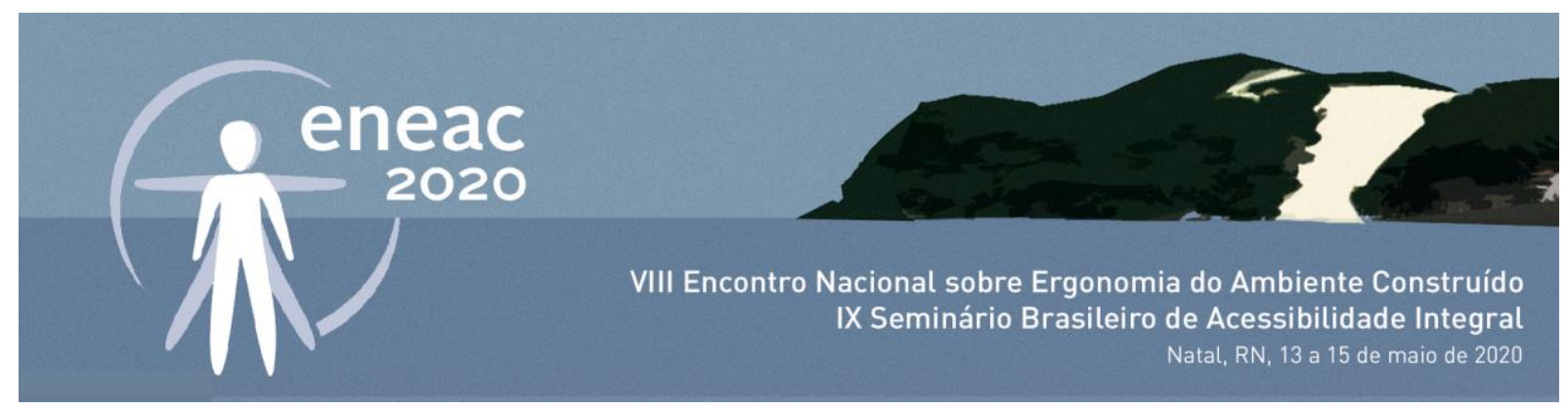

ENCONTRO NACIONAL DE ERGONOMIA NO AMBIENTE CONSTRUÍDO E SEMINÁRIO BRASILEIRO DE ACESSIBILIDADE INTEGRAL, 6., 2016, Recife. Anais eletrônicos [...]. Recife: UFPE, 2016. Disponível em:

https://www.proceedings.blucher.com.br/article-list/eneac2016-267/list\#articles>. Acesso em: 15 de fev. de 2019.

ENCONTRO NACIONAL DE ERGONOMIA NO AMBIENTE CONSTRUÍDO E SEMINÁRIO BRASILEIRO DE ACESSIBILIDADE INTEGRAL, 7., 2018, Fortaleza. Anais eletrônicos [...]. Fortaleza: UFC. Disponível em:

https://www.proceedings.blucher.com.br/article-list/eneac-303/list\#articles>. Acesso em: 15 de fev. de 2019.

ORNSTEIN, S.W. (Org.); PRADO, A.R. (Org.); LOPES, M.E. (Org). Desenho universal: caminhos da acessibilidade no Brasil. São Paulo: Annablume, 2010.

ZEVI, Bruno. Saber ver a arquitetura. São Paulo: Martins Fontes, 2000.

ABNT - ASSOCIAÇÃO BRASILEIRA DE NORMAS TÉCNICAS. NBR 9050. Rio de Janeiro, 2015.

VILLAROUCO, Vilma. Reflexões sobre a Ergonomia aplicada aos ambientes construídos e caminhos percorridos. In: MONT'ALVÃO, Cláudia; VILLAROUCO, Vilma. Um novo olhar para o projeto: ergonomia no ambiente construído. Olinda: Livro Rápido, 2018.p.(11)- (23).

ABERGO. Ação Ergonômica, 2019. Disponível em: <http://www.abergo.org.br>. Acesso em: 20 de jan. de 2020. 